(2) Open Access Full Text Article

\title{
Future directions in combined modality therapy for rectal cancer: reevaluating the role of total mesorectal excision after chemoradiotherapy
}

This article was published in the following Dove Press journal:

OncoTargets and Therapy

13 August 2013

Number of times this article has been viewed

\section{Abhishek A Solanki' \\ Daniel T Chang ${ }^{2}$ \\ Stanley L Liauw'}

'Department of Radiation and Cellular Oncology, University of Chicago, Chicago, IL, USA; ${ }^{2}$ Department of Radiation Oncology, Stanford University, Stanford, CA, USA
Correspondence: Stanley L Liauw Department of Radiation and Cellular Oncology, 5758 S Maryland Avenue, MC 9006, Chicago, IL 60637, USA

Tel +I 7737026870

Fax +I 7738347340

Email sliauw@radonc.uchicago.edu

\begin{abstract}
Most patients who develop rectal cancer present with locoregionally advanced (T3 or node-positive) disease. The standard management of locoregionally advanced rectal cancer is neoadjuvant concurrent chemoradiotherapy (nCRT), followed by radical resection (low-anterior resection or abdominoperineal resection with total mesorectal excision). Approximately $15 \%$ of patients can have a pathologic complete response (pCR) at the time of surgery, indicating that some patients can have no detectable residual disease after nCRT. The actual benefit of surgery in this group of patients is unclear. It is possible that omission of surgery in these patients, termed selective nonoperative management, can limit the toxicities associated with standard, multimodal combined modality therapy without compromising disease control. In this review, we discuss the clinical experiences to date using selective nonoperative management and various attempts at escalation of nCRT to improve the number of patients who have a pCR. We also explore several clinical, laboratory, imaging, histopathologic, and genetic biomarkers that have been tested as tools to predict which patients are most likely to have a pCR after nCRT.
\end{abstract}

Keywords: rectal cancer, chemoradiotherapy, total mesorectal excision, nonoperative management, organ preservation

\section{Introduction}

Up to $70 \%$ of patients with nonmetastatic rectal cancer present with locoregionally advanced disease. ${ }^{1}$ Locally advanced rectal cancer (LARC) is generally defined as T3 or node-positive rectal cancer. The standard of care for LARC in the United States is neoadjuvant concurrent chemoradiotherapy (nCRT) given with conventional fractionation over 6 weeks, followed by radical resection with total mesorectal excision (TME) and adjuvant chemotherapy.

With TME, there can be up to a $2 \%$ mortality rate. Length of hospital admissions average 15 days. ${ }^{2,3}$ The incidence of morbidity ranges from $6 \%$ to $35 \%$, which includes anastomotic leak, pain, and blood loss from the procedure. ${ }^{4}$ Between $20 \%$ and $40 \%$ of patients have severe sexual dysfunction after surgery. ${ }^{5,6}$ There are also compelling data regarding the effect of resection on quality of life. Patients undergoing abdominoperineal resection (APR), in particular, have reported decreased quality of life. ${ }^{7}$ According to Pachler and Wille-Jørgensen, it is unclear whether low-anterior resection minimizes this decline in quality of life compared with APR. ${ }^{8}$

Because many reports indicate that approximately $15 \%$ of patients with LARC have a pathologic complete response (pCR) to neoadjuvant therapy at the time of surgery, ${ }^{9}$ it is reasonable to wonder whether the risks of TME outweigh the benefits in this select group of patients. Select series indeed show excellent long-term outcomes 
in patients who have a pCR to nCRT without subsequent TME, suggesting that it is possible to avoid planned, radical resection in some patients..$^{9,10}$ A review by O'Neill et al discussed some of the key issues that must be addressed in pursuing such an approach in patients with LARC. ${ }^{11}$ In this review, we describe the rationale and clinical experiences using selective nonoperative management (SNOM), highlight avenues to improve the efficacy of nCRT to render more patients with a pCR, and explore potential biomarkers associated with response to nCRT that could help identify optimal candidates for SNOM.

\section{Methods}

We performed a review of the literature concerning selective nonoperative management in LARC by searching MEDLINE for English-language articles to identify studies with the following subject matter: "rectal cancer", "neoadjuvant chemoradiotherapy", "pathologic complete response", "selective nonoperative management after neoadjuvant chemoradiotherapy", "radiotherapy dose escalation", "chemotherapy escalation and novel combinations", and "clinical, imaging, and biologic biomarkers predicting for response to treatment". Retrospective cohort and casecontrol series, as well as prospective cohort and Phase I, II, and III clinical trials, were included in our review.

\section{PCR as an indicator of long-term outcomes}

The ideal candidates for SNOM are patients with the best responses to nCRT. pCR, or the complete eradication of macroscopic and microscopic tumor as judged by histopathologic evaluation of the specimen from the radical resection, is the most desirable outcome after nCRT. In the German CAO/ ARO/AIO-94 randomized Phase III trial of preoperative versus postoperative CRT on which the current standard of therapy of preoperative chemoradiotherapy is based, $8 \%$ of patients had a pCR after preoperative therapy. ${ }^{12}$ Of these patients, only $2.9 \%$ developed a local recurrence at 10 years after TME. Several large series demonstrate that patients with a pCR at the time of surgery have substantially improved long-term local control, distant control, and disease-free survival (DFS; Table 1). ${ }^{9,10,13}$ It is unclear how much radical resection contributes to the low rate of local recurrence in patients with a pCR. Unfortunately, there are no randomized data that directly compare outcomes with or without surgical excision in this group of patients, and proper identification of patients with a $\mathrm{pCR}$ without performing radical resection and detailed histopathologic analysis is difficult. Despite these issues, using the pCR as a surrogate for the ultimate response may help identify the patients who are most appropriate for SNOM.

\section{Clinical experiences exploring SNOM}

The most extensive clinical experience using SNOM is from Sao Paulo, Brazil. There have been multiple publications on the outcomes of patients treated at two institutions in Brazil: the University of Sao Paulo Medical School, Sao Paulo and the Angelita and Joaquim Gama Institute, Sao Paulo. ${ }^{14-18}$ Eligibility included T3-4 disease, node-positive or T2 distal rectal tumors that would otherwise require an APR. In the initial reports, staging was performed via physical exam, digital rectal examination (DRE), rigid proctoscopy, chest

Table I 5-year outcomes in a large series evaluating disease outcomes in patients with rectal cancer obtaining a pathologic complete response to neoadjuvant chemoradiotherapy

\begin{tabular}{|c|c|c|c|c|}
\hline Group (n) & $\begin{array}{l}\text { Local recurrence } \\
\text { at } 5 \text { years }\end{array}$ & $\begin{array}{l}\text { Distant metastasis } \\
\text { at } 5 \text { years }\end{array}$ & $\begin{array}{l}\text { Recurrence-free } \\
\text { survival at } 5 \text { years }\end{array}$ & $\begin{array}{l}\text { Overall survival } \\
\text { at } 5 \text { years }\end{array}$ \\
\hline \multicolumn{5}{|l|}{ Irish meta-analysis ${ }^{10}$} \\
\hline $\mathrm{pCR}(\mathrm{n}=1263)$ & $3 \%$ & $11 \%$ & $83 \%$ & $88 \%$ \\
\hline No $p C R(n=2100)$ & $10 \%$ & $25 \%$ & $66 \%$ & $76 \%$ \\
\hline$P$-value & $<0.001$ & $<0.00 \mathrm{I}$ & $<0.001$ & $<0.001$ \\
\hline \multicolumn{5}{|l|}{ Dutch pooled analysis9 } \\
\hline $\mathrm{pCR}(\mathrm{n}=484)$ & $1 \%$ & $9 \%$ & $87 \%$ & $90 \%$ \\
\hline \multicolumn{5}{|l|}{ MD Anderson ${ }^{13}$} \\
\hline $\operatorname{PCR}(n=|3|)$ & $1 \%$ & $7 \%$ & $91 \%$ & $93 \%$ \\
\hline $\begin{array}{l}\text { Intermediate response } \\
(\mathrm{n}=210)\end{array}$ & $2 \%$ & $10 \%$ & $79 \%$ & $87 \%$ \\
\hline Poor response $(n=384)$ & $9 \%$ & $27 \%$ & $59 \%$ & $77 \%$ \\
\hline$P$-value & 0.002 & $<0.001$ & $<0.001$ & 0.002 \\
\hline
\end{tabular}

Note: Intermediate response, yрTI-2 N0; poor response, yрT3-4 or ypNI-2.

Abbreviation: $\mathrm{PCR}$, pathologic complete response. 
X-ray, computed tomography (CT) abdomen/pelvis, and serum carcinoembryonic antigen (CEA). ${ }^{14,15}$ Patients were treated with 50.4 Gy and concurrent 5-fluorouracil (5-FU) and leucovorin. ${ }^{14,15}$ Response assessment was performed by a colorectal surgeon 8 weeks after nCRT, using the same staging modalities. Patients who were felt to have a complete clinical response (cCR), which was defined as no significant residual ulcer and no positive biopsy, did not undergo surgery. Instead, they had monthly physical exam, DRE, proctoscopy, biopsy if feasible, and serum CEA assessment for the first year, which was increased to every 2 months for the second year and then 6 months for the third year. CT abdomen/pelvis and chest $\mathrm{X}$-ray were repeated every 6 months for the first year.

In their largest report comparing operative with nonoperative management, Habr-Gama et al demonstrated favorable results of SNOM. ${ }^{14}$ Of 265 patients treated with nCRT, the outcomes of 22 patients with a pCR after surgery were compared with the outcomes of 71 patients who had a cCR for at least 12 months. There was no difference in 5-year overall survival (OS) or DFS between patients. Importantly, there were no cancer-related mortalities in the nonoperative group. Two (3\%) patients had endorectal recurrences, both of whom were salvaged (one with brachytherapy and one with transanal excision). A subsequent analysis of 361 patients using the same protocol provided more insight into the patterns of failure of patients treated with SNOM (Table 2). ${ }^{15}$ Of 122 patients who had a cCR to nCRT (34\% of the entire cohort), 99 (81\%) maintained a cCR for 1 year. Patients with endorectal-only failures (5\%) were successfully salvaged without further recurrence, and none died of rectal cancer.

Over time, the Brazilian protocol has evolved. ${ }^{17,18}$ Patients are currently additionally staged using pelvic magnetic resonance imaging (MRI) or endorectal ultrasound (ERUS). ${ }^{19}$ Patients are treated with 54 Gy rather than 50.4 Gy and receive three cycles of adjuvant chemotherapy and reassessment at 10 weeks. Patients with any suspicious areas undergo full-thickness local excision for diagnostic purposes. Although the definition likely evolved over the course of the published studies, a strict definition of cCR has been published by Habr-Gama et al. ${ }^{20}$ Patients with any residual deep ulceration, any superficial ulcer or irregularity (even if only mucosal), or any palpable nodule on DRE are considered to have an incomplete clinical response, whereas those with no palpable abnormality, white discoloration of mucosal surface, telangiectasia, or subtle loss of pliability of the rectal wall could be considered as having a cCR.

There are some limitations to the Brazilian experience. The outcomes of patients who initially achieved a cCR but had a recurrence within the first year (who were excluded from analysis) have not clearly been discussed. Poor outcomes in these patients could sway one away from SNOM. In addition, stage I patients are not typically treated with nCRT and have more favorable outcomes than those with LARC, yet $11 \%$ of patients in the latter paper had stage I (T2N0) disease, potentially favorably biasing the results. ${ }^{15}$

Several other institutions have reported the outcomes of their patients who were treated with SNOM. Table 2 describes these outcomes. ${ }^{21-24}$ Maas et al reported excellent outcomes in their patients treated with SNOM. ${ }^{21}$ In this study, patients with a cCR $(n=21)$ were compared with 20 patients with a pCR at surgery. Nearly half $(10 / 21)$ of the patients treated nonoperatively would have required an APR, and all had sphincter preservation, whereas nearly half (9/20) of those in the surgical group required permanent colostomy. One of the patients developed a local recurrence in the nonoperative group, whereas none did in the operative group. This patient with recurrence had a transanal excision with complete resection. The cumulative 2-year DFS was $89 \%$ versus $93 \%$, and 2 -year OS was $100 \%$ versus $91 \%$, for the nonoperative and surgical groups, respectively, with differences that were not statistically significant. A series from Memorial Sloan-Kettering Cancer Center found that when comparing 32 patients treated with nonoperative management with 57 patients with pCR at surgery, patients treated without surgery had a higher risk of local recurrence (19\%; $\mathrm{n}=6) .{ }^{22}$ However, all recurrences were successfully salvaged with surgery, and there was no difference in DFS, distant metastasis, or survival between the two groups. Two series from the United Kingdom have also evaluated SNOM as a treatment approach, but neither of these studies compared the outcomes of these patients with those of patients treated with planned surgery. ${ }^{23,24}$

There are several limitations to the published experiences of SNOM. The most important issue is that the bulk of the data come from small, retrospective, single-institution series with relatively short follow-up. In addition, most studies included patients with earlier-stage disease (some cT2N0 patients). The favorable outcome of these patients may have made the outcomes of the nonoperative group appear more favorable than would be expected for LARC. An important point to highlight is that the patients in these relatively small cohorts may have been carefully selected for consideration of nonoperative management based on location and size. For example, in the series by Habr-Gama et al, approximately $72 \%$ of patients had N0 disease, and mean tumor size was $3.8 \mathrm{~cm} .{ }^{15}$ It is difficult to translate these results to patients with 


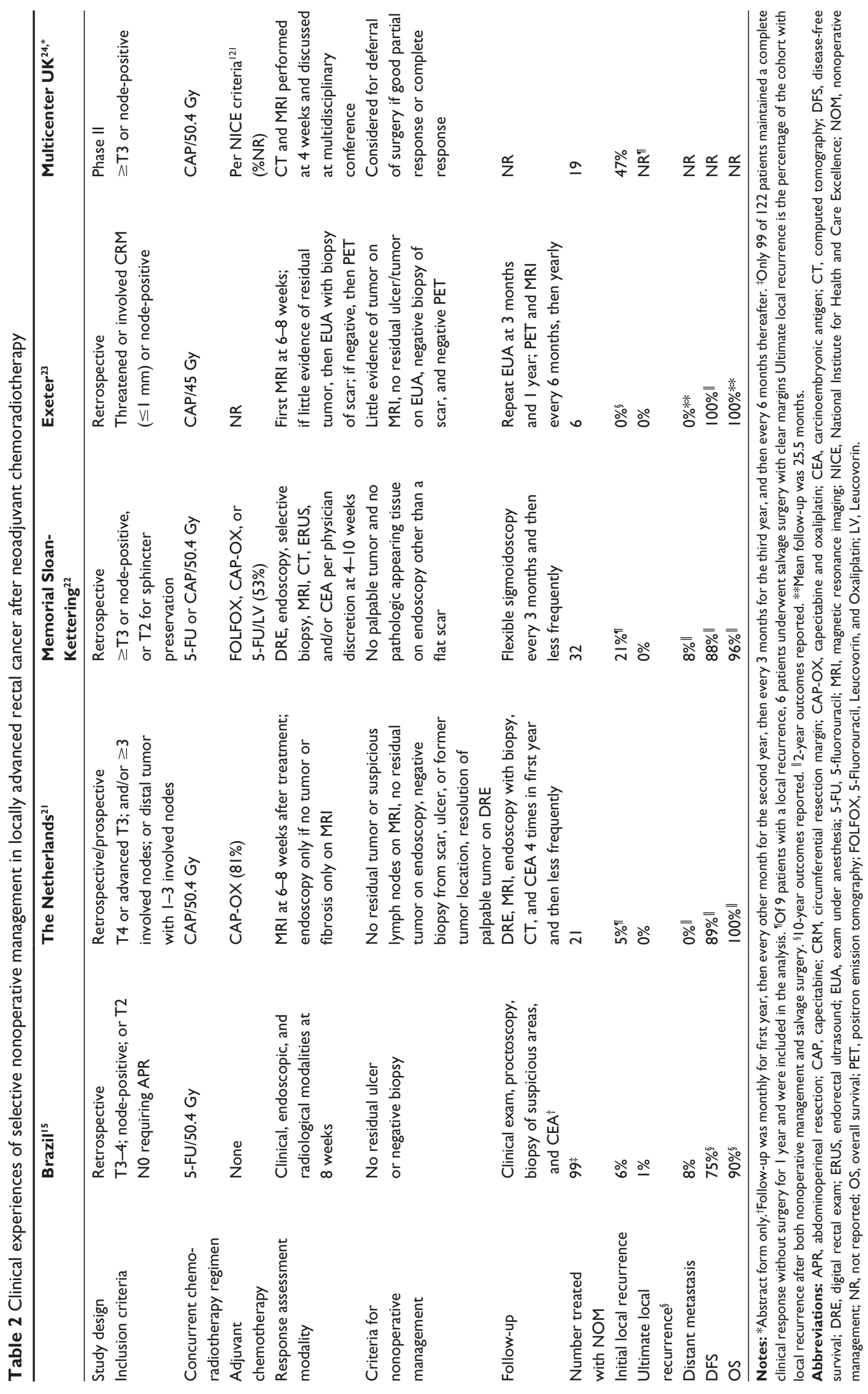


higher and more advanced tumors with a clinical complete response. In addition, the proportion of patients who achieved a cCR after nCRT in each of these studies was relatively low (10\%-34\%). ${ }^{15,21,23}$ The definition of cCR, methods of determining response, follow-up frequency, and clinical/imaging modalities to assess for recurrence differ from study to study. In the series that compares the outcomes of nonoperative with operative patients, the patients selected as controls are those with a pCR after radical surgery. As discussed later, $\mathrm{cCR}$ does not necessarily correlate with $\mathrm{pCR}$, and thus these control groups may not be the optimal comparison group for the nonoperative $\mathrm{cCR}$ patients.

Before SNOM can be implemented in routine practice, more robust data are necessary. Ultimately, a randomized trial comparing the two approaches would provide the strongest evidence, but a large cohort study with structured and longterm follow-up could also be useful to better define the outcomes with SNOM. A more ideal comparison would involve patients with cCR (rather than $\mathrm{pCR}$ ), using prospectively defined criteria, who are then either observed or resected.

\section{Efforts to improve the efficacy of $n$ CRT}

It is likely that to be a candidate for SNOM, a patient needs to have at least a cCR to treatment. The $10-34 \% \mathrm{cCR}$ rates in the above studies, as well as the $15 \%$ pCR rate, suggest that only a minority of patients are potential candidates for SNOM. Advances in chemotherapy and radiation therapy could improve these rates and increase the proportion of patients eligible for SNOM.

\section{Radiation dose escalation and altered fractionation}

One way to improve the pCR rate after nCRT is to intensify radiotherapy (RT). Conventional RT is typically given as 1.8-2 Gy per fraction once a day until the total dose is reached. Altered RT fractionation, which refers to changes in the daily dose and total treatment time, has been attempted to improve the response to RT. Short-course RT is unlikely to be the preferred approach for SNOM because it results in a low $\mathrm{pCR}$ rate. Two randomized studies compared long-course RT (50.4 Gy) with short-course RT (25 Gy) followed by radical resection. ${ }^{25,26}$ Disease control outcomes and reported toxicity between the two regimens were similar, but the $\mathrm{pCR}$ rate was higher in the 50.4 Gy group than in the 25 Gy group in both studies (15-16\% compared with 1\%). A caveat to this is that the short time after completion of RT to resection ( 1 week) could have limited the number of pCRs in the short-course RT group. If they had undergone surgery later, more pCRs may have been detected. ${ }^{27}$ Radiation Therapy Oncology Group (RTOG) 0012 evaluated a hyperfractionated schema of 55.2-60 Gy in 1.2 Gy fractions twice daily with concurrent 5-FU compared with 50.4-54 Gy with conventional fractionation and 5-FU and irinotecan. ${ }^{28}$ The rate of pCR was high for both groups $(26 \%)$; there was no statistically significant difference.

Several attempts have been made to improve pCR and disease control outcomes using RT dose escalation (Table 3). Among patients treated with long-course RT, there appears to be a benefit in dose escalation from 40 to 50 Gy. A study of patients treated in three consecutive RT dose schedules found that with increasing dose from 40 to $50 \mathrm{~Gy}$, the pCR rates, local control, cause-specific survival, and progression-free survival improved. ${ }^{29}$ Mohiuddin et al found that patients treated with more than 55 Gy and continuous infusion 5-FU had a substantially higher $\mathrm{pCR}$ rate compared with those receiving less than 50 Gy $(44 \%$ versus $13 \% ; P=0.05) .{ }^{30}$ In a series by Wiltshire et al, patients treated with 46 Gy or more had improved local recurrence-free survival, DFS, and OS compared with patients treated with $40 \mathrm{~Gy}$, but escalation to $50 \mathrm{~Gy}$ did not improve outcomes. ${ }^{31}$ Unfortunately, most of the above series indicate that with elevated dose, there is also increased toxicity, potentially limiting the applicability of high RT doses.

Increasing the RT dose with modalities other than External Beam RT (EBRT) has also been assessed. Unlike EBRT, which is the use of X-rays to deliver radiation to tumors, brachytherapy refers to the placement of radioisotopes within or near tumor tissues, and contact X-ray RT (CXR) is the use of a narrow beam of low-energy photon radiation placed in close proximity to tumor tissues. Both of these specialized modalities have the advantage of limiting dose to surrounding normal tissues in comparison with a multifield, EBRT approach. The role of using these modalities as a boost to escalate RT dose from EBRT has not been established. A randomized trial comparing 50.4 Gy versus 50.4 Gy with 10 Gy endorectal high-dose-rate brachytherapy boost found no difference in $\mathrm{pCR}$ rate ( $18 \%$ in both groups). ${ }^{32}$ In contrast, a randomized trial of EBRT compared with EBRT with CXR boost revealed improved pathologic response (defined as no, or few residual cells at the time of surgery) in the high-dose group. ${ }^{33}$ Of note, CXR therapy for rectal cancer has been primarily studied for low-lying and less advanced tumors; the applicability of this treatment approach to more advanced or more proximal tumors is unclear.

Newer technologies, such as intensity-modulated radiotherapy (IMRT), may allow for safer RT dose escalation. 
Table 3 Radiotherapy dose escalation studies in locally advanced rectal cancer

\begin{tabular}{|c|c|c|c|c|c|c|}
\hline Study & $\mathbf{N}$ & Key inclusion criteria & Study design & nCRT regimen & PCR & Toxicity \\
\hline Polish $^{25}$ & 312 & $\begin{array}{l}\text { T3-4, resectable tumor, } \\
\text { no sphincter involvement }\end{array}$ & $\begin{array}{l}\text { Phase III, } \\
\text { randomized }\end{array}$ & $\begin{array}{l}\text { 5-FU/50.4 Gy versus } \\
25 \mathrm{~Gy}\end{array}$ & $\begin{array}{l}16 \% \text { versus } 1 \% \\
(P=N R)\end{array}$ & $\begin{array}{l}\text { Severe late: } 7 \% \text { versus } \\
10 \%(P=0.36)\end{array}$ \\
\hline TROG $^{26}$ & 326 & cT3 tumor & $\begin{array}{l}\text { Phase III, } \\
\text { randomized }\end{array}$ & $\begin{array}{l}\text { 5-FU/50.4 Gy versus } \\
25 \mathrm{~Gy}\end{array}$ & $\begin{array}{l}15 \% \text { versus } 1 \% \\
(P=0.22)\end{array}$ & $\begin{array}{l}\text { Late grade } 3-4: 8 \% \\
\text { versus } 6 \%(P=0.53)\end{array}$ \\
\hline Calgary ${ }^{29}$ & 156 & $\begin{array}{l}\text { Locally advanced rectal } \\
\text { cancer }\end{array}$ & Retrospective & $\begin{array}{l}5-\mathrm{FU} / 40 \mathrm{~Gy} \text { versus } \\
5-\mathrm{FU}+\mathrm{LV}+\mathrm{MMC} / 40 \mathrm{~Gy} \\
\text { versus } 5-\mathrm{FU}+\mathrm{LV} / 50 \mathrm{~Gy}\end{array}$ & $\begin{array}{l}4 \% \text { versus } 15 \% \\
\text { versus } 25 \% \\
(P<0.002)\end{array}$ & $\begin{array}{l}\text { Increased grade } 2 \text { skin and } \\
\text { Gl morbidity with each } \\
\text { successive schedule }\end{array}$ \\
\hline Kentucky ${ }^{30}$ & 33 & Fixed tumor & Retrospective & $\begin{array}{l}\text { 5-FU/45-50 Gy versus } \\
5-\mathrm{FU} / 55-60 \text { Gy }\end{array}$ & $\begin{array}{l}13 \% \text { versus } 44 \% \\
(P=0.05)\end{array}$ & $\begin{array}{l}\text { Grade } 3: 33 \% \text { in entire } \\
\text { cohort }\end{array}$ \\
\hline $\begin{array}{l}\text { Princess } \\
\text { Margaret }^{31}\end{array}$ & 134 & T3-4 or NI-2 & $\begin{array}{l}3 \text { Phase II trials, } \\
\text { nonrandomized }\end{array}$ & $\begin{array}{l}\text { 5-FU/40 Gy versus } \\
\text { 5-FU/46 Gy versus } \\
\text { 5-FU/50 Gy }\end{array}$ & $\begin{array}{l}15 \% \text { versus } 23 \% \\
\text { versus } 33 \% \\
(P=0.07)\end{array}$ & $\begin{array}{l}\text { Grade } 3-4: 13 \% \text { versus } \\
4 \% \text { versus } 14 \%(P=0.20)\end{array}$ \\
\hline $\begin{array}{l}\text { Lyon } \\
\text { R96-02 }\end{array}$ & 88 & $\begin{array}{l}\text { T2-3 involving } \leq 2 / 3 \\
\text { circumference }\end{array}$ & $\begin{array}{l}\text { Phase III, } \\
\text { randomized }\end{array}$ & $\begin{array}{l}39 \mathrm{~Gy}^{\dagger} \text { versus } \\
39 \mathrm{~Gy}+85 \mathrm{~Gy} \text { CXR }\end{array}$ & $\begin{array}{l}7 \% \text { versus } \\
21 \%(P=N R)\end{array}$ & $\begin{array}{l}\text { Similar acute radiotherapy } \\
\text { and surgical complications } \\
\text { in both groups }\end{array}$ \\
\hline Denmark ${ }^{32}$ & 248 & $\begin{array}{l}\text { T3-4, resectable, with } \\
\text { MRI circumferential } \\
\text { margin }<5 \mathrm{~mm}\end{array}$ & $\begin{array}{l}\text { Phase III, } \\
\text { randomized }\end{array}$ & $\begin{array}{l}\text { UFT + LV/50.4 Gy versus } \\
\text { UFT + LV/50.4 Gy + } 10 \text { Gy } \\
\text { HDR brachytherapy }\end{array}$ & $\begin{array}{l}18 \% \text { versus } \\
18 \%(P=N S)\end{array}$ & $\begin{array}{l}\text { Grade } \geq 2 \text { nonheme: } \\
40 \% \text { versus } 50 \%\end{array}$ \\
\hline Colorado ${ }^{38}$ & 8 & Stage II-III & $\begin{array}{l}\text { Phase II, } \\
\text { nonrandomized }\end{array}$ & CAP/55 Gy IMRT & $38 \%$ & $\begin{array}{l}\text { Grade } 4 \text { diarrhea }=13 \% \\
\text { no other grade } \geq 3 \text { toxicity }\end{array}$ \\
\hline Fox Chase ${ }^{39}$ & 8 & T3-4 or NI-2 & $\begin{array}{l}\text { Phase I, } \\
\text { nonrandomized }\end{array}$ & CAP/55 Gy IMRT & $0 \%$ & Grade 3 toxicity $=38 \%$ \\
\hline
\end{tabular}

Notes: *Received 18 Gy post-operatively. ${ }^{\dagger}$ Optional $25-G y$ brachytherapy boost.

Abbreviations: CAP, capecitabine; CXR, contact X-ray therapy; 5-FU, 5-fluorouracil; GI, gastrointestinal; heme, hematologic; HDR, high dose rate; IMRT, intensitymodulated radiotherapy; LV, leucovorin; MMC, mitomycin C; MRI, magnetic resonance imaging; nCRT, neoadjuvant chemoradiotherapy; NR, not reported; NS, not significant; PCR, pathologic complete response; TROG, TransTasman Radiation Oncology Group; UFT, uftoral.

IMRT uses advanced planning and delivery techniques that can reduce the amount of high-dose radiation to normal tissues by varying the intensity of radiation delivered in each field. This normal tissue sparing has the potential to minimize toxicity because most adverse effects of radiation are a result of high doses to normal tissues. Several series show that IMRT decreases doses to critical normal organs and may thus safely allow for further dose escalation. ${ }^{34,35}$ De Ridder et al and Engels et al performed a Phase II study of 108 patients with cT3-4 tumors treated with neoadjuvant RT alone, using an IMRT and simultaneous integrated boost (SIB) approach with helical tomotherapy. ${ }^{36,37}$ Patients with anticipated close circumferential resection margins received 55.2 Gy, whereas the others received $46 \mathrm{~Gy}$. Both groups were treated to a smaller treatment volume to allow for small bowel sparing. The pCR rate was $8 \%$, but a favorable acute toxicity profile was noted in comparison with that seen for previously reported, standard RT techniques. A small Phase II study of eight patients treated using a simultaneous integrated boost approach to 55 Gy in $2.2 \mathrm{~Gy} /$ fraction to gross tumor found three of eight patients had a pCR. ${ }^{38}$ However, a Phase I study of eight patients at Fox Chase Cancer Center (Philadelphia, PA, USA) found unacceptable toxicity ( $38 \%$ had grade 3 toxicity) with a similar treatment approach, albeit with larger treatment volumes. ${ }^{39}$
The small sample sizes of these studies limit the ability to make conclusions regarding the risk-benefit ratio of dose escalation with IMRT.

The effect of regional hyperthermia to $\mathrm{nCRT}$ on response has also been assessed in several series. In a retrospective review of 106 patients, Schroeder et al found that patients treated with the addition of regional hyperthermia had improved pCR rates (16.4\% versus $6.7 \%) .{ }^{40}$ However, two single-group Phase II studies combining hyperthermia with nCRT found similar pCR compared with nCRT alone. ${ }^{41,42}$ Therefore, the role of hyperthermia is unclear.

\section{Chemotherapy agent, dose, and timing modifications}

The backbone of concurrent chemotherapy in the nCRT regimen has traditionally been 5-FU. Importantly, the schedule in which the drug is administered has been shown to affect its efficacy. Continuous infusional 5-FU has been shown to be more effective than bolus 5-FU in the metastatic setting and adjuvant concurrent CRT setting ${ }^{43,44}$ and has therefore been adopted as the standard chemotherapy schedule when given as nCRT. An attractive alternative to infusional 5-FU is the oral fluoropyrimidine, capecitabine, which likely is at least equivalent to 5-FU, if not better. In a randomized 
Phase III trial, capecitabine was associated with a trend toward improved $\mathrm{pCR}$ rate ( $14 \%$ versus $5 \% ; P=0.09)$, 3-year DFS (71\% versus $63 \% ; P=$ not reported), and 5 -year survival (66\% versus $61 \% ; P=$ not reported) in patients treated with nCRT for LARC. ${ }^{45}$

Despite encouraging Phase II studies, Phase III studies combining other agents with capecitabine or 5-FU have mostly not improved pCR rates (Table 4). Although several trials showed no benefit for the addition of oxaliplatin, ${ }^{46-48}$ the German CAO/ARO/AIO-04 randomized Phase 3 trial showed a modest improvement in $\mathrm{pCR} .{ }^{49} \mathrm{RTOG} 0012$ revealed no benefit in pCR with the addition of irinotecan. ${ }^{28} \mathrm{~A}$ singlegroup Phase II study of 25 patients demonstrated an encouraging $\mathrm{pCR}$ rate of $32 \%$ with the addition of bevacizumab to capecitabine and 50.4 Gy but must be confirmed in a larger randomized trial. ${ }^{50}$ Adding cetuximab to nCRT does not appear to improve pCR. ${ }^{51,52}$

Additional chemotherapy after nCRT and before surgical resection has also been investigated. A follow-up study by Habr-Gama et al included 29 patients treated with three extra cycles of bolus 5-FU and leucovorin after nCRT. ${ }^{17} \mathrm{cCR}$ at 10 weeks was $76 \%(n=22)$, and of these, $63 \%(n=14)$ had a

Table 4 Addition of combination chemotherapy agents to 5-FU- or CAP-based nCRT

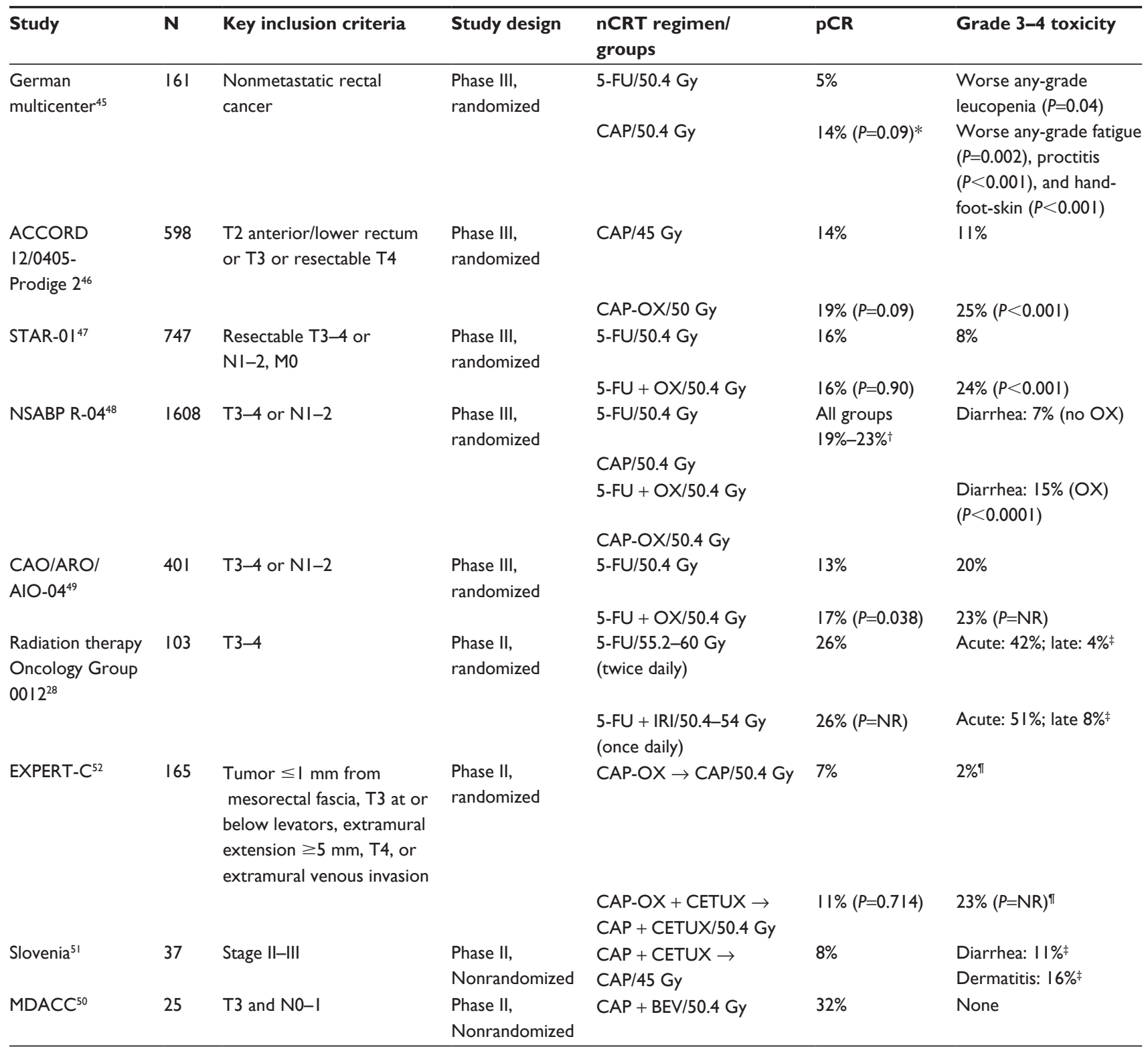

Notes: *Capecitabine was also associated with a trend toward improved 3-year disease-free survival and 5 -year overall survival in the neoadjuvant chemoradiotherapy cohort. ${ }^{\dagger 5}$-FU based: $19 \%$ versus capecitabine-based: $23 \%$ ( $\left.P=0.012\right)$, oxaliplatin-based: $19 \%$ versus non-oxaliplatin-based: $21 \%(P=0.46)$. ${ }^{\ddagger}$ Grade 3 only. ${ }^{\top}$ Grades $3-5$. Abbreviations: CAP, capecitabine; BEV, bevacizumab; CAP-OX, capecitabine + oxaliplatin; CETUX, cetuximab; 5-FU, 5-fluorouracil; IRI, irinotecan; nCRT, neoadjuvant chemoradiotherapy; NR, not reported; OX, oxaliplatin; PCR, pathologic complete response; $\rightarrow$, followed by. 
cCR for 1 year. It is important to note that in this study, $17 \%$ of patients had stage I disease. A nonrandomized multicenter Phase II trial treated patients with nCRT, followed by 2 cycles of modified FOLFOX-6 (5-fluorouracil, leucovorin, and oxaliplatin) if a cCR by imaging and proctoscopy was achieved after nCRT. ${ }^{53}$ Patients treated with post-nCRT chemotherapy had a higher rate of $\mathrm{pCR}$ at the time of TME compared with patients who had standard nCRT followed by TME (25\% versus $18 \%)$, but this difference was not statistically significant.

\section{Identifying the best responders}

For SNOM to be successful, it is imperative to identify patients who have a pCR after nCRT without radical resection. Various methods are used to assess those who are most likely to have an excellent response, including clinical factors, physical exam findings, and laboratory and genetic factors. Here, we discuss various modalities of assessment and their strengths and weaknesses.

\section{Clinical parameters}

Several clinical factors have been associated with improved response to nCRT. One series found higher $\mathrm{pCR}$ rates for less rectal wall circumference involvement and lower pCR rates for tumors involving more than $60 \%$ of the circumference and being more than $5 \mathrm{~cm}$ from anal verge. ${ }^{54}$ Although some studies suggest that initial clinical T-stage and N-stage may be associated with response, ${ }^{5,56}$ others suggest that these characteristics may not be as important as genetic factors. ${ }^{57,58}$

It is possible that treatment response (and factors that may influence response) are dependent on time between nCRT and surgery. A longer interval between nCRT and radical surgery may improve pCR rates, and this delay of resection may not compromise local control. ${ }^{16,27,59,60} \mathrm{~A}$ randomized study from Lyon found that pathologic downstaging was increased when the interval between RT and surgery was increased from 2 weeks to $6-8$ weeks (10\% versus $26 \%$; $P=0.005)$, although the primary endpoint of sphincterpreserving surgery was not significantly different. ${ }^{61}$ Even patients treated with short-course RT can have a pCR rate of $8 \%$ if surgery occurs after 4 weeks (compared with $1 \%$ at 1 week). ${ }^{62}$ However, in the Brazilian experience, using conventional nCRT followed by surgery, patients who had more than 12 weeks delay had no difference in pCR, DFS, or survival compared with those who had surgery at 12 weeks or less. ${ }^{16}$ The current National Comprehensive Cancer Network guideline is an interval between $\mathrm{nCRT}$ and radical resection of 5-10 weeks. ${ }^{63}$
Clinical assessment is the most commonly used form of post-treatment response assessment. A review from Memorial Sloan-Kettering of patients treated with nCRT followed by resection evaluated post-treatment DRE and proctoscopy to evaluate clinical response to CRT and found that only $25 \%$ of patients with cCR actually had a pCR, which was generally 6 weeks after nCRT (with response assessment 1 week before surgery). ${ }^{64}$ Another study found that complete response by DRE only correctly identified pCR in $21 \%$ of patients with a $\mathrm{pCR} .{ }^{65}$ In addition, many patients with $\mathrm{pCR}$ may have residual mucosal abnormality at the time of response assessment. ${ }^{66}$ For patients who have what appears to be an incomplete clinical response, a series from Perez et al found that $21 \%$ of patients with a negative endoscopic biopsy actually had a pCR. ${ }^{67}$ These findings make post-treatment physical exam findings even more difficult to use in decision making. For these reasons, pretreatment clinical parameters, physical exam findings after treatment, and post-treatment biopsy are not sufficient to predict pCR.

\section{Imaging modalities}

Several imaging modalities are commonly used in the initial staging and response assessment of patients with rectal cancer, including CT and ERUS. The ability of ERUS and $\mathrm{CT}$ to individually predict for pCR both at the primary and nodes is relatively modest. ${ }^{68-70}$ An Italian series of 46 patients compared ERUS, CT, and MRI at 4 weeks after nCRT. In this study, radiographic staging by ERUS or CT that indicated no residual abnormality in the rectal wall was considered $\mathrm{T} 0$, tumor felt to be confined to the rectal wall was called $\mathrm{T} 1$ or T2, full-thickness involvement of the rectal wall with infiltration of the perirectal fat was T3, and invasion of surrounding organs/structures was T4. Lymph nodes $5 \mathrm{~mm}$ or larger were considered to be positive. The accuracy was $64 \%$ for ERUS and $74 \%$ for CT in predicting pT0 status, and $61 \%$ for ERUS and $62 \%$ for CT for predicting pN0 status. ${ }^{69}$

MRI is a promising imaging modality to evaluate anatomic changes after nCRT. Still, RT fibrosis can make interpretation difficult, and although MRI is effective for identifying disease that only involves the rectal wall, it cannot reliably identify patients with pCR. In the Italian series, the accuracy of MRI at 4 weeks after nCRT for pT0 was $77 \%$, and for pN0 it was $65 \% .{ }^{69}$ The Magnetic Resonance Imaging and Rectal Cancer European Equivalence (MERCURY) study was a prospective cohort study of patients treated with nCRT followed by surgical resection. ${ }^{71}$ In this study, an MRI tumor regression grade (mrTRG) was created based on the TRG for histopathologic response. ${ }^{72}$ Although the mrTRG 
was useful for detecting unfavorable pathologic response (ypT3-4 or TRG 0-2), it is unclear whether it can predict pCR at surgery. ${ }^{73}$ In addition, only $44 \%$ of patients had a favorable response (ypT0-3a) in this study at the time of histopathologic evaluation, and only $11 \%$ had pCR. This highlights the minority of patients who would be applicable for SNOM with the current treatment platform and MRI response assessment.

Positron emission tomography (PET) offers insight into the metabolic activity of tissues, potentially complementing anatomic imaging. A Brazilian study found a 73\% negative predictive value and $85 \%$ accuracy of PET/CT for detecting incomplete response. ${ }^{74}$ Other studies have suggested PET may not be as accurate. ${ }^{75,76}$ A prospective study of 80 patients treated with nCRT followed by radical resection found that PET/CT did not predict pathologic response, but a decrease in SUV (standardized uptake value) was associated with lower disease recurrence. ${ }^{77}$ These clinical data, as well as the issue of interobserver variation and no clear standard criteria for response assessment, suggest that the use of PET or PET/CT alone to predict $\mathrm{pCR}$ has questionable utility.

Individually, each of these imaging modalities does not appear to be suitable to identify patients with a pCR. However, when combined, they have greater prognostic value. In the Brazilian series, the accuracy of PET/CT combined with clinical exam was $96 \%$ in predicting $\mathrm{pCR} .{ }^{74}$ In a Taiwanese series of 166 patients, using MRI, colonoscopy, and rebiopsy to reassess patients at 4 weeks after nCRT, the accuracy was $78 \%$ for $\mathrm{pCR} .{ }^{78}$ However, it is important to note that the majority of data using multimodality reassessment are retrospective in nature, are subject to selection bias, and may be influenced by expertise.

\section{CEA and other laboratory findings}

Several studies have evaluated whether clinical response assessment can be augmented by pre-and post-treatment CEA levels. One study found that pretreatment CEA levels higher than $5 \mathrm{ng} / \mathrm{mL}$ were associated with a poor response to nCRT. ${ }^{57}$ Another study found that patients with a pCR had a lower pretreatment and post-treatment CEA level, and that no patients with an elevated post-treatment CEA ( $>5 \mathrm{ng} / \mathrm{mL}$ ) level had a pCR. ${ }^{79}$ In this series, post-treatment CEA levels had a stronger association with outcome than pretreatment levels. Another series found that pre-nCRT versus post-nCRT CEA changes were not associated with pCR rate, but those patients with high pretreatment CEA and poor reduction $(<70 \%)$ after nCRT had a higher risk for local and distant recurrence. ${ }^{80} \mathrm{~A}$ Brazilian series found that patients with post-treatment CEA levels lower than $5 \mathrm{ng} / \mathrm{mL}$ had higher rates of cCR, pCR, DFS, and OS than those who did not. ${ }^{81}$ Ultimately, a standard definition of "low" CEA or "good" response must be identified for optimal use of CEA in treatment decision making.

Other laboratory tests have also been evaluated. Kawai et al found that pre-nCRT thrombocytosis was associated with worse response by barium enema, or pathologic response. ${ }^{82}$ Kitayama et al found that patients who had a complete response had higher lymphocyte ratios and lower neutrophil ratios, suggesting that part of the response to nCRT may be immune-mediated. ${ }^{83}$ These series hint that other lab parameters may be of use but must be validated in other series before they may be used clinically.

\section{Tumor histopathologic markers}

Numerous histopathologic markers have been evaluated to identify patients who will have a good response to nCRT and/ or good prognosis (Table 5). ${ }^{84-105}$ None have been identified as unequivocal biomarkers of response across all studies. Most biomarkers have been found to be associated with both improved and inferior response in different studies. Most of the studies are small, single-institution series; few are validated externally; and varying nCRT regimens were used. The most extensively studied marker has involved p53 mutations. ${ }^{106-108}$ A meta-analysis found that wild-type p53 was associated with improved rates of "good response." 109 Despite these positive findings, neither p53 nor any of the other studied biomarkers are likely to singularly predict for those destined to have a $\mathrm{pCR}$. The response to treatment is likely too complex to be modeled adequately with one biomarker.

Table 5 Investigated histopathologic factors possibly associated with response to neoadjuvant chemoradiotherapy

\begin{tabular}{ll}
\hline Marker of interest & References \\
\hline p53 & $106-109$ \\
Thymidylate synthase & $84-87$ \\
Epidermal growth factor receptor & $86,88-91$ \\
Bax & $84,92,93$ \\
Ki-67 & $84,94,95,98$ \\
p2I & 96,97 \\
Vascular endothelial growth factor & 91,98 \\
Remodeling and spacing factor I & 99 \\
Matrix metallopeptidase 9 & 100 \\
Insulin-like growth factor 2 mRNA-binding protein 3 & 101 \\
HMG-coA synthase 2 & 102 \\
PIK3CA & 103 \\
XRCCI polymorphism & 104 \\
Cox2 overexpression & 105 \\
\hline
\end{tabular}

Abbreviations: $\mathrm{Bax}, \mathrm{BCl}$-2-associated $\mathrm{X}$ protein; HMG, 3-hydroxyl-3-methyl-glutarylCoA; PIK3CA, phosphatidylinositol-4, 5-bisphosphate 3-kinase catalytic subunit alpha isoform; $\mathrm{XRCCl}, \mathrm{X}$-ray repair cross-complementing protein I; Cox2, cyclooxygenase-2. 


\section{Gene and microRNA expression profiles}

Several groups have identified tumor gene expression profiles that may be associated with response to nCRT. ${ }^{110-112}$ Interestingly, the gene expression profiles in these studies do not necessarily highlight genes known to be important. Kim et al specifically identified a gene expression profile that identified pCR with $84 \%$ accuracy in a testing sample and $87 \%$ accuracy in a validation cohort. ${ }^{113}$ This profile was composed of 95 genes involved in multiple cellular pathways, including MMP14, MSX2, RAD23B, Thymidylate synthase, FGFR4, and ENO1. Similarly, micro (mi)RNA expression profiles may be associated with response to therapy. ${ }^{114,115}$ An Italian study found a miRNA expression profile that predicted $\mathrm{pCR}$ with a sensitivity and specificity of $100 \%{ }^{116}$ This study included 38 patients with LARC treated with capecitabine and oxaliplatin with 45 Gy RT. Biopsy specimens were analyzed to identify a 13-miRNA expression profile composed of eleven miRNAs that were upregulated and two miRNAs that were downregulated in pCR patients. All of the nine patients with a pCR had upregulation of miR-630 and miR-622, whereas all patients without a pCR had downregulation of these two miRNAs. However, this profile has not been confirmed externally and may not be practical because detailed knowledge regarding individual miRNA levels of expression is required. These findings are encouraging, but further research is necessary to identify and validate the optimal profile to translate it into clinical use.

\section{Circulating/disseminated tumor cells}

Circulating tumor cells (CTCs), or tumor cells identified in the peripheral blood, and disseminated tumor cells, tumor cells identified in the bone marrow, have also been evaluated for their role in response prediction. There are no series evaluating whether the presence, concentration, or changes in concentration before or after nCRT of CTCs can identify patients who are likely to have a pCR. One of the challenges with using CTCs as a biomarker for response is that only $30-60 \%$ of patients with rectal cancer have detectable CTCs. ${ }^{117,118}$ An Austrian study found that CTCs were more likely to be detected in patients with a good response to nCRT (ypT0-2) than in nonresponders at the time of surgery $(63 \%$ versus $18 \%$ ), and responders had decreased detection over the course of treatment. ${ }^{17}$ A Norwegian study found that disseminated tumor cell detection was not associated with radiologic TNM stage or TRG score at the time of surgery after nCRT. ${ }^{118}$

\section{Circulating cell-free DNA}

Circulating cell-free DNA (cfDNA) is another promising biomarker. Agostini et al studied 67 patients undergoing nCRT and found that the post-treatment cfDNA integrity index and levels of Alu 247 fragments were independently associated with improved response rate. ${ }^{119}$ Similarly, Zitt et al found that responders had lower levels of cfDNA after treatment compared to nonresponders. ${ }^{120}$ However, these findings must be validated, and the ability of cfDNA parameters to predict pCR is unknown.

\section{Toward the development of a SNOM protocol}

A standardized approach toward SNOM of rectal cancer has yet to be defined. All of the SNOM series discussed earlier differ in the frequency of follow-up and modalities of initial staging and response assessment. It is likely that even if the merits of a SNOM approach are confirmed in further studies, the optimal protocol would be the subject of much debate. It is clear that the ideal protocol would have comprehensive staging with clinical examination, colonoscopy, and imaging such as ERUS, MRI, and PET-CT both before starting nCRT and for tumor response assessment. The optimal chemoRT regimen is unknown, but $50.4 \mathrm{~Gy}$ with FU is not sufficient to achieve meaningful rates of pCR. Patients must be followed frequently. On the basis of the Habr-Gama and Dutch series, it appears that the highest risk for recurrence is within the first year after treatment, when follow-up would need to be closest. In the second year, the frequency of follow-up could be decreased, with gradual relaxation up to 5 years. Long-term follow-up would be essential to establish safety, given the possibility for late recurrences ${ }^{12}$ and potential for late toxicity in the intact rectum. Further protocols should also include biomarkers, such as CTCs or cfDNA, which may better predict for pCR and improved outcome. In addition, newer imaging modalities, such as novel PET tracers, should be incorporated, as traditional imaging modalities have limitations in predicting $\mathrm{pCR}$. The ideal timing of surgery in those without a $\mathrm{cCR}$ is also unknown. It appears that anywhere from 8 to 12 weeks or more may be safe, but the incremental delay in surgery to potentially allow for increased appreciation of pCR must be weighed against the increased risk of recurrence. However, patients who do reach this point with a cCR could be considered appropriate for omission of surgery.

\section{Conclusion}

Several series suggest that SNOM is safe and feasible in a small proportion of patients with locally advanced 
rectal cancer. However, the literature describing this approach is mostly retrospective and single-institution in nature, with small numbers and varied methodology. In addition, many of these studies lack long-term follow-up. These issues limit the ability to consider SNOM a safe alternative to the standard treatment paradigm. Larger prospective studies with long-term follow-up, ideally randomized prospective trials comparing standard combined modality therapy with SNOM, are necessary to further evaluate the safety and efficacy of this approach. Until more robust studies confirm its appropriateness, SNOM cannot be incorporated into routine practice. Even if further study supports SNOM of rectal cancer, perhaps only a minority of patients will obtain the cCR necessary to pursue SNOM using current nCRT regimens and response assessment tools. Further research is necessary to improve the efficacy of nCRT to induce a complete response. Simultaneously, oncologists must better identify patients who have had a pCR, as current assessment and detection approaches have demonstrated insufficient accuracy to alter treatment. There are biomarkers with encouraging preliminary results, however, which must be validated and confirmed in larger, multicenter cohorts. With progress in these areas, perhaps SNOM will not only be feasible and safe but also be the approach of choice in a subset of patients with LARC.

\section{Disclosure}

The authors report no conflicts of interest in this work.

\section{References}

1. Gunderson LL, Jessup JM, Sargent DJ, Greene FL, Stewart A. Revised tumor and node categorization for rectal cancer based on surveillance, epidemiology, and end results and rectal pooled analysis outcomes. J Clin Oncol. 2010;28(2):256-263.

2. Hartley JE, Mehigan BJ, Qureshi AE, Duthie GS, Lee PW, Monson JR. Total mesorectal excision: assessment of the laparoscopic approach. Dis Colon Rectum. 2001;44(3):315-321.

3. Lujan J, Valero G, Hernandez Q, Sanchez A, Frutos MD, Parrilla P. Randomized clinical trial comparing laparoscopic and open surgery in patients with rectal cancer. Br J Surg. 2009;96(9):982-989.

4. Breukink S, Pierie J, Wiggers T. Laparoscopic versus open total mesorectal excision for rectal cancer. Cochrane Database Syst Rev. 2006;18(4):CD005200

5. Cornish JA, Tilney HS, Heriot AG, Lavery IC, Fazio VW, Tekkis PP. A meta-analysis of quality of life for abdominoperineal excision of rectum versus anterior resection for rectal cancer. Ann Surg Oncol. 2007;14(7):2056-2068.

6. Jayne DG, Brown JM, Thorpe H, Walker J, Quirke P, Guillou PJ. Bladder and sexual function following resection for rectal cancer in a randomized clinical trial of laparoscopic versus open technique. $\mathrm{Br} J$ Surg. 2005;92(9):1124-1132.

7. Kasparek MS, Hassan I, Cima RR, Larson DR, Gullerud RE, Wolff BG. Long-term quality of life and sexual and urinary function after abdominoperineal resection for distal rectal cancer. Dis Colon Rectum. 2012;55(2):147-154.
8. Pachler J, Wille-Jørgensen P. Quality of life after rectal resection for cancer, with or without permanent colostomy. Cochrane Database Syst Rev. 2012;12:CD004323.

9. Maas M, Nelemans PJ, Valentini V, et al. Long-term outcome in patients with a pathological complete response after chemoradiation for rectal cancer: a pooled analysis of individual patient data. Lancet Oncol. 2010;11(9):835-844.

10. Martin ST, Heneghan HM, Winter DC. Systematic review and metaanalysis of outcomes following pathological complete response to neoadjuvant chemoradiotherapy for rectal cancer. Br J Surg. 2012;99(7): 918-928.

11. O'Neill BD, Brown G, Heald RJ, Cunningham D, Tait DM. Nonoperative treatment after neoadjuvant chemoradiotherapy for rectal cancer. Lancet Oncol. 2007;8(7):625-633.

12. Sauer R, Liersch T, Merkel S, et al. Preoperative versus postoperative chemoradiotherapy for locally advanced rectal cancer: results of the German CAO/ARO/AIO-94 randomized Phase III trial after a median follow-up of 11 years. J Clin Oncol. 2012;30(16):1926-1933.

13. Park IJ, You YN, Agarwal A, et al. Neoadjuvant treatment response as an early response indicator for patients with rectal cancer. J Clin Oncol. 2012;30(15):1770-1776.

14. Habr-Gama A, Perez RO, Nadalin W, et al. Operative versus nonoperative treatment for stage 0 distal rectal cancer following chemoradiation therapy: long-term results. Ann Surg. 2004;240(4):711-717.

15. Habr-Gama A, Perez RO, Proscurshim I, et al. Patterns of failure and survival for nonoperative treatment of stage $\mathrm{c} 0$ distal rectal cancer following neoadjuvant chemoradiation therapy. J Gastrointest Surg. 2006;10(10):1319-1328.

16. Habr-Gama A, Perez RO, Proscurshim I, et al. Interval between surgery and neoadjuvant chemoradiation therapy for distal rectal cancer: does delayed surgery have an impact on outcome? Int J Radiat Oncol Biol Phys. 2008;71(4):1181-1188.

17. Habr-Gama A, Perez RO, Sabbaga J, Nadalin W, São Julião GP, Gama-Rodrigues J. Increasing the rates of complete response to neoadjuvant chemoradiotherapy for distal rectal cancer: results of a prospective study using additional chemotherapy during the resting period. Dis Colon Rectum. 2009;52(12):1927-1934.

18. Habr-Gama A, Perez RO, São Julião GP, Proscurshim I, Gama-Rodrigues J. Nonoperative approaches to rectal cancer: a critical evaluation. Semin Radiat Oncol. 2011;21(3):234-239.

19. Habr-Gama A, Perez RO, Lynn PB, Sao Juliao GP, Gama-Rodrigues J. Selective non-operative management of distal rectal cancer: the Watch and Wait Protocol. In: Schiessel R. MP, editor. Intersphincteric Resection for Low Tumors of the Rectum. New York: Springer-Verlag/Wien; 2012:43-53.

20. Habr-Gama A, Perez RO, Wynn G, Marks J, Kessler H, Gama-Rodrigues J. Complete clinical response after neoadjuvant chemoradiation therapy for distal rectal cancer: characterization of clinical and endoscopic findings for standardization. Dis Colon Rectum. 2010;53(12):1692-1698.

21. Maas M, Beets-Tan RG, Lambregts DM, et al. Wait-and-see policy for clinical complete responders after chemoradiation for rectal cancer. J Clin Oncol. 2011;29(35):4633-4640.

22. Smith JD, Ruby JA, Goodman KA, et al. Nonoperative management of rectal cancer with complete clinical response after neoadjuvant therapy. Ann Surg. 2012;256(6):965-972.

23. Dalton RS, Velineni R, Osborne ME, et al. A single-centre experience of chemoradiotherapy for rectal cancer: is there potential for nonoperative management? Colorectal Dis. 2012;14(5):567-571.

24. Yu SK, Brown G, Heald RJ, et al. Deferral of rectal surgery following a continued response to preoperative chemoradiotherapy (Watch and Wait) study: a Phase II multicenter study in the United Kingdom [abstract]. J Clin Oncol. 2011;29(suppl 4):abstract 489.

25. Bujko K, Nowacki MP, Nasierowska-Guttmejer A, Michalski W, Bebenek M, Kryj M. Long-term results of a randomized trial comparing preoperative short-course radiotherapy with preoperative conventionally fractionated chemoradiation for rectal cancer. Br J Surg. 2006;93(10): $1215-1223$. 
26. Ngan SY, Burmeister B, Fisher RJ, et al. Randomized trial of shortcourse radiotherapy versus long-course chemoradiation comparing rates of local recurrence in patients with T3 rectal cancer: Trans-Tasman Radiation Oncology Group trial 01.04. J Clin Oncol. 2012 1;30(31): 3827-3833.

27. Kalady MF, de Campos-Lobato LF, Stocchi L, et al. Predictive factors of pathologic complete response after neoadjuvant chemoradiation for rectal cancer. Ann Surg. 2009;250(4):582-589.

28. Mohiuddin M, Winter K, Mitchell E, et al; Radiation Therapy Oncology Group Trial 0012. Randomized Phase II study of neoadjuvant combinedmodality chemoradiation for distal rectal cancer: Radiation Therapy Oncology Group Trial 0012. J Clin Oncol. 2006;24(4):650-655.

29. Chan AK, Wong AO, Langevin J, et al. Preoperative chemotherapy and pelvic radiation for tethered or fixed rectal cancer: a Phase II dose escalation study. Int J Radiat Oncol Biol Phys. 2000;48(3):843-856.

30. Mohiuddin M, Regine WF, John WJ, et al. Preoperative chemoradiation in fixed distal rectal cancer: dose time factors for pathological complete response. Int J Radiat Oncol Biol Phys. 2000;46(4):883-888.

31. Wiltshire KL, Ward IG, Swallow C, et al. Preoperative radiation with concurrent chemotherapy for resectable rectal cancer: effect of dose escalation on pathologic complete response, local recurrence-free survival, disease-free survival, and overall survival. Int J Radiat Oncol Biol Phys. 2006;64(3):709-716.

32. Jakobsen A, Ploen J, Vuong T, Appelt A, Lindebjerg J, Rafaelsen SR. Dose-effect relationship in chemoradiotherapy for locally advanced rectal cancer: a randomized trial comparing two radiation doses. Int $J$ Radiat Oncol Biol Phys. 2012;84(4):949-954.

33. Gerard JP, Chapet O, Nemoz C, et al. Improved sphincter preservation in low rectal cancer with high-dose preoperative radiotherapy: the lyon R96-02 randomized trial. J Clin Oncol. 2004;22(12):2404-2409.

34. Arbea L, Ramos LI, Martínez-Monge R, Moreno M, Aristu J. Intensitymodulated radiation therapy (IMRT) versus 3D conformal radiotherapy (3DCRT) in locally advanced rectal cancer (LARC): dosimetric comparison and clinical implications. Radiat Oncol. 2010 26;5:17.

35. Guerrero Urbano MT, Henrys AJ, Adams EJ, et al. Intensity-modulated radiotherapy in patients with locally advanced rectal cancer reduces volume of bowel treated to high dose levels. Int J Radiat Oncol Biol Phys. 2006;65(3):907-916.

36. De Ridder M, Tournel K, Van Nieuwenhove Y, et al. Phase II study of preoperative helical tomotherapy for rectal cancer. Int J Radiat Oncol Biol Phys. 2008;70(3):728-734.

37. Engels B, Tournel K, Everaert H, et al. Phase II study of preoperative helical tomotherapy with a simultaneous integrated boost for rectal cancer. Int J Radiat Oncol Biol Phys. 2012;83(1):142-148.

38. Ballonoff A, Kavanagh B, McCarter M, et al. Preoperative capecitabine and accelerated intensity-modulated radiotherapy in locally advanced rectal cancer: a Phase II trial. Am J Clin Oncol. 2008;31(3):264-270.

39. Freedman GM, Meropol NJ, Sigurdson ER, et al. Phase I trial of preoperative hypofractionated intensity-modulated radiotherapy with incorporated boost and oral capecitabine in locally advanced rectal cancer. Int J Radiat Oncol Biol Phys. 2007;67(5):1389-1393.

40. Schroeder C, Gani C, Lamprecht U, et al. Pathological complete response and sphincter-sparing surgery after neoadjuvant radiochemotherapy with regional hyperthermia for locally advanced rectal cancer compared with radiochemotherapy alone. Int $J$ Hyperthermia. 2012;28(8):707-714.

41. Barsukov YA, Gordeyev SS, Tkachev SI, Fedyanin MY, Perevoshikov AG. Phase II study of concomitant chemoradiotherapy with local hyperthermia and metronidazole for locally advanced fixed rectal cancer. Colorectal Dis. Epub May 14, 2013.

42. Rau B, Wust P, Hohenberger P, et al. Preoperative hyperthermia combined with radiochemotherapy in locally advanced rectal cancer: a Phase II clinical trial. Ann Surg. 1998;227(3):380-389.

43. O'Connell MJ, Martenson JA, Wieand HS, et al. Improving adjuvant therapy for rectal cancer by combining protracted-infusion fluorouracil with radiation therapy after curative surgery. $N$ Engl $J$ Med. 1994;331(8):502-507.
44. O'Connell MJ, Martenson JA, Wieand HS, et al. Efficacy of intravenous continuous infusion of fluorouracil compared with bolus administration in advanced colorectal cancer. Meta-analysis Group in Cancer. $J$ Clin Oncol. 1998;16(1):301-308.

45. Hofheinz RD, Wenz F, Post S, et al. Chemoradiotherapy with capecitabine versus fluorouracil for locally advanced rectal cancer: a randomised, multicentre, non-inferiority, Phase 3 trial. Lancet Oncol. 2012;13(6):579-588.

46. Gérard JP, Azria D, Gourgou-Bourgade S, et al. Comparison of two neoadjuvant chemoradiotherapy regimens for locally advanced rectal cancer: results of the Phase III trial ACCORD 12/0405-Prodige 2.J Clin Oncol. 2010;28(10):1638-1644.

47. Aschele C, Cionini L, Lonardi S, et al. Primary tumor response to preoperative chemoradiation with or without oxaliplatin in locally advanced rectal cancer: pathologic results of the STAR-01 randomized Phase III trial. J Clin Oncol. 2011;29(20):2773-2780.

48. Roh MS, Yothers GA, O'Connell MJ, et al. The impact of capecitabine and oxaliplatin in the preoperative multimodality treatment in patients with carcinoma of the rectum: NSABP R-04. J Clin Oncol. 2011;29(Suppl):Abstract 3503.

49. Rödel C, Liersch T, Becker H, et al; German Rectal Cancer Study Group. Preoperative chemoradiotherapy and postoperative chemotherapy with fluorouracil and oxaliplatin versus fluorouracil alone in locally advanced rectal cancer: initial results of the German CAO/ARO/AIO-04 randomised Phase 3 trial. Lancet Oncol. 2012;13(7):679-687.

50. Crane $\mathrm{CH}$, Eng C, Feig BW, et al. Phase II trial of neoadjuvant bevacizumab, capecitabine, and radiotherapy for locally advanced rectal cancer. Int J Radiat Oncol Biol Phys. 2010;76(3):824-830.

51. Velenik V, Ocvirk J, Oblak I, Anderluh F. A Phase II study of cetuximab, capecitabine and radiotherapy in neoadjuvant treatment of patients with locally advanced resectable rectal cancer. Eur J Surg Oncol. 2010;36(3):244-250.

52. Dewdney A, Cunningham D, Tabernero J, et al. Multicenter randomized Phase II clinical trial comparing neoadjuvant oxaliplatin, capecitabine, and preoperative radiotherapy with or without cetuximab followed by total mesorectal excision in patients with high-risk rectal cancer (EXPERT-C). J Clin Oncol. 2012;30(14):1620-1627.

53. Garcia-Aguilar J, Smith DD, Avila K, Bergsland EK, Chu P, Krieg RM; Timing of Rectal Cancer Response to Chemoradiation Consortium. Optimal timing of surgery after chemoradiation for advanced rectal cancer: preliminary results of a multicenter, nonrandomized Phase II prospective trial. Ann Surg. 2011;254(1):97-102.

54. Das P, Skibber JM, Rodriguez-Bigas MA, et al. Predictors of tumor response and downstaging in patients who receive preoperative chemoradiation for rectal cancer. Cancer. 2007;109(9):1750-1755.

55. Yoon SM, Kim DY, Kim TH, et al. Clinical parameters predicting pathologic tumor response after preoperative chemoradiotherapy for rectal cancer. Int J Radiat Oncol Biol Phys. 2007;69(4): $1167-1172$.

56. Moureau-Zabotto L, Farnault B, de Chaisemartin C, et al. Predictive factors of tumor response after neoadjuvant chemoradiation for locally advanced rectal cancer. Int J Radiat Oncol Biol Phys. 2011;80(2): 483-491.

57. Park YA, Sohn SK, Seong J, et al. Serum CEA as a predictor for the response to preoperative chemoradiation in rectal cancer. J Surg Oncol. 2006;93(2):145-150.

58. Park $\mathrm{CH}$, Kim HC, Cho YB, et al. Predicting tumor response after preoperative chemoradiation using clinical parameters in rectal cancer. World J Gastroenterol. 2011;17(48):5310-5316.

59. Tulchinsky H, Shmueli E, Figer A, Klausner JM, Rabau M. An interval $>7$ weeks between neoadjuvant therapy and surgery improves pathologic complete response and disease-free survival in patients with locally advanced rectal cancer. Ann Surg Oncol. 2008;15(10): 2661-2667.

60. Evans J, Tait D, Swift I, et al. Timing of surgery following preoperative therapy in rectal cancer: the need for a prospective randomized trial? Dis Colon Rectum. 2011;54(10):1251-1259. 
61. Francois Y, Nemoz CJ, Baulieux J, et al. Influence of the interval between preoperative radiation therapy and surgery on downstaging and on the rate of sphincter-sparing surgery for rectal cancer: the Lyon R90-01 randomized trial. J Clin Oncol. 1999;17(8):2396.

62. Pettersson D, Holm T, Iversen H, Blomqvist L, Glimelius B, Martling A. Preoperative short-course radiotherapy with delayed surgery in primary rectal cancer. Br J Surg. 2012;99(4):577-583.

63. NCCN Guidelines: Rectal Cancer Version 4.2013 [webpage on the Internet]. Fort Washington, PA: National Comprehensive Cancer Network; 2012. Available from: http://www.nccn.org/professionals/ physician_gls/pdf/rectal.pdf. Accessed March 8, 2013.

64. Hiotis SP, Weber SM, Cohen AM, et al. Assessing the predictive value of clinical complete response to neoadjuvant therapy for rectal cancer: an analysis of 488 patients. J Am Coll Surg. 2002;194(2):131-135.

65. Guillem JG, Chessin DB, Shia J, et al. Clinical examination following preoperative chemoradiation for rectal cancer is not a reliable surrogate end point. J Clin Oncol. 2005;23(15):3475-3479.

66. Smith FM, Chang KH, Sheahan K, Hyland J, O'Connell PR, Winter DC. The surgical significance of residual mucosal abnormalities in rectal cancer following neoadjuvant chemoradiotherapy. Br J Surg. 2012;99(7):993-1001.

67. Perez RO, Habr-Gama A, Pereira GV, et al. Role of biopsies in patients with residual rectal cancer following neoadjuvant chemoradiation after downsizing: can they rule out persisting cancer? Colorectal Dis. 2012;14(6):714-720.

68. Huh JW, Park YA, Jung EJ, Lee KY, Sohn SK. Accuracy of endorectal ultrasonography and computed tomography for restaging rectal cancer after preoperative chemoradiation. J Am Coll Surg. 2008;207(1):7-12.

69. Maretto I, Pomerri F, Pucciarelli S, et al. The potential of restaging in the prediction of pathologic response after preoperative chemoradiotherapy for rectal cancer. Ann Surg Oncol. 2007;14(2):455-461.

70. Pomerri F, Pucciarelli S, Gennaro G, Maretto I, Nitti D, Muzzio PC. Comparison between CT volume measurement and histopathological assessment of response to neoadjuvant therapy in rectal cancer. Eur $J$ Radiol. 2012;81(12):3918-3924.

71. Patel UB, Taylor F, Blomqvist L, et al. Magnetic resonance imagingdetected tumor response for locally advanced rectal cancer predicts survival outcomes: MERCURY experience. J Clin Oncol. 2011;29(28): 3753-3760.

72. Dworak O, Keilholz L, Hoffmann A. Pathological features of rectal cancer after preoperative radiochemotherapy. Int $J$ Colorectal Dis. 1997;12(1):19-23

73. Patel UB, Brown G, Rutten H, et al. Comparison of magnetic resonance imaging and histopathological response to chemoradiotherapy in locally advanced rectal cancer. Ann Surg Oncol. 2012;19(9):2842-2852.

74. Perez RO, Habr-Gama A, Gama-Rodrigues J, et al. Accuracy of positron emission tomography/computed tomography and clinical assessment in the detection of complete rectal tumor regression after neoadjuvant chemoradiation: long-term results of a prospective trial (National Clinical Trial 00254683). Cancer. 2012;118(14):3501-3511.

75. Guillem JG, Ruby JA, Leibold T, et al. Neither FDG-PET nor CT is able to distinguish between a pathological complete response and an incomplete response after neoadjuvant chemoradiation in locally advanced rectal cancer: a prospective study. Ann Surg. Epub November 26, 2012.

76. Ruby JA, Leibold T, Akhurst TJ, et al. FDG-PET assessment of rectal cancer response to neoadjuvant chemoradiotherapy is not associated with long-term prognosis: a prospective evaluation. Dis Colon Rectum. 2012;55(4):378-386.

77. Martoni AA, Di Fabio F, Pinto C, et al. Prospective study on the FDG-PET/CT predictive and prognostic values in patients treated with neoadjuvant chemoradiation therapy and radical surgery for locally advanced rectal cancer. Ann Oncol. 2011;22(3):650-656.

78. Kuo LJ, Chiou JF, Tai CJ, et al. Can we predict pathologic complete response before surgery for locally advanced rectal cancer treated with preoperative chemoradiation therapy? Int J Colorectal Dis. 2012;27(5): 613-621.
79. Song S, Hong JC, McDonnell SE, et al. Combined modality therapy for rectal cancer: the relative value of posttreatment versus pretreatment CEA as a prognostic marker for disease recurrence. Ann Surg Oncol. 2012;19(8):2471-2476.

80. Kim CW, Yu CS, Yang SS, et al. Clinical significance of pre- to postchemoradiotherapy s-CEA reduction ratio in rectal cancer patients treated with preoperative chemoradiotherapy and curative resection. Ann Surg Oncol. 2011;18(12):3271-3277.

81. Perez RO, São Julião GP, Habr-Gama A, et al. The role of carcinoembriogenic antigen in predicting response and survival to neoadjuvant chemoradiotherapy for distal rectal cancer. Dis Colon Rectum. 2009;52(6):1137-1143.

82. Kawai K, Kitayama J, Tsuno NH, Sunami E, Watanabe T. Thrombocytosis before pre-operative chemoradiotherapy predicts poor response and shorter local recurrence-free survival in rectal cancer. Int J Colorectal Dis. 2013;28(4):527-535.

83. Kitayama J, Yasuda K, Kawai K, Sunami E, Nagawa H. Circulating lymphocyte number has a positive association with tumor response in neoadjuvant chemoradiotherapy for advanced rectal cancer. Radiat Oncol. 2010;5:47.

84. Kikuchi M, Mikami T, Sato T, et al. High Ki67, Bax, and thymidylate synthase expression well correlates with response to chemoradiation therapy in locally advanced rectal cancers: proposal of a logistic model for prediction. Br J Cancer. 2009;101(1):116-123.

85. Arrazubi V, Suárez J, Guerrero D, et al. Prognostic significance of thymidylate synthase polymorphisms in rectal cancer patients treated with neoadjuvant chemoradiotherapy. Colorectal Dis. 2013;15(4): 428-435.

86. Spindler KL, Nielsen JN, Lindebjerg J, Brandslund I, Jakobsen A. Prediction of response to chemoradiation in rectal cancer by a gene polymorphism in the epidermal growth factor receptor promoter region. Int J Radiat Oncol Biol Phys. 2006;66(2):500-504.

87. Spindler KL, Nielsen JN, Lindebjerg J, Jakobsen A. Germline polymorphisms may act as predictors of response to preoperative chemoradiation in locally advanced $\mathrm{T} 3$ rectal tumors. Dis Colon Rectum. 2007;50(9):1363-1369.

88. Giralt J, de las Heras M, Cerezo L, et al; Grupo Español de Investigacion Clinica en Oncologia Radioterápica (GICOR). The expression of epidermal growth factor receptor results in a worse prognosis for patients with rectal cancer treated with preoperative radiotherapy: a multicenter, retrospective analysis. Radiother Oncol. 2005;74(2):101-108.

89. Kim JS, Kim JM, Li S, et al. Epidermal growth factor receptor as a predictor of tumor downstaging in locally advanced rectal cancer patients treated with preoperative chemoradiotherapy. Int J Radiat Oncol Biol Phys. 2006;66(1):195-200.

90. Dvorak J, Sitorova V, Ryska A, et al. [Prognostic significance of changes of tumor epidermal growth factor receptor expression after neoadjuvant chemoradiation in patients with rectal adenocarcinoma.] Strahlenther Onkol. 2012;188(9):833-838. German.

91. Zlobec I, Vuong T, Compton CC, Lugli A, et al. Combined analysis of VEGF and EGFR predicts complete tumour response in rectal cancer treated with preoperative radiotherapy. Br J Cancer. 2008;98(2): 450-456.

92. Chang HJ, Jung KH, Kim DY, et al. Bax, a predictive marker for therapeutic response to preoperative chemoradiotherapy in patients with rectal carcinoma. Hum Pathol. 2005;36(4):364-371.

93. Huerta S, Hrom J, Gao X, et al. Tissue microarray constructs to predict a response to chemoradiation in rectal cancer. Dig Liver Dis. 2010;42(10):679-684

94. Fluge Ø, Gravdal K, Carlsen E, et al; Norwegian Gastrointestinal Cancer Group. Expression of EZH2 and $\mathrm{Ki}-67$ in colorectal cancer and associations with treatment response and prognosis. Br J Cancer. 2009;101(8):1282-1289.

95. Terzi C, Canda AE, Sagol O, et al. Survivin, p53, and Ki-67 as predictors of histopathologic response in locally advanced rectal cancer treated with preoperative chemoradiotherapy. Int $J$ Colorectal Dis. 2008;23(1):37-45. 
96. Sturm I, Rau B, Schlag PM, et al. Genetic dissection of apoptosis and cell cycle control in response of colorectal cancer treated with preoperative radiochemotherapy. BMC Cancer. 2006;6:124.

97. Suzuki T, Sadahiro S, Tanaka A, et al. Biopsy specimens obtained 7 days after starting chemoradiotherapy (CRT) provide reliable predictors of response to CRT for rectal cancer. Int J Radiat Oncol Biol Phys. 2013;85(5):1232-1238.

98. Yan H, Wang R, Yu J, et al. Predictive value of Smac, VEGF and Ki-67 in rectal cancer treated with neoadjuvant therapy. Oncol Lett. 2010;1(4):641-647.

99. Lin CY, Tian YF, Wu LC, et al. Rsf-1 expression in rectal cancer: with special emphasis on the independent prognostic value after neoadjuvant chemoradiation. J Clin Pathol. 2012;65(8):687-692.

100. Unsal Kilic D, Uner A, Akyurek N, Erpolat P, Dursun A, Pak Y. Matrix metalloproteinase-9 expression correlated with tumor response in patients with locally advanced rectal cancer undergoing preoperative chemoradiotherapy. Int J Radiat Oncol Biol Phys. 2007;67(1):196-203.

101. Lochhead P, Imamura Y, Morikawa T, et al. Insulin-like growth factor 2 messenger RNA binding protein 3 (IGF2BP3) is a marker of unfavourable prognosis in colorectal cancer. Eur J Cancer. 2012;48(18):3405-3413.

102. Yeo SG, Kim DY, Kim KH, et al. Hydroxymethylglutaryl-coenzyme a synthase 2 expression is associated with chemoradiotherapy responses in colorectal cancer. Dis Colon Rectum. 2012;55(6):686-694.

103. He Y, Van't Veer LJ, Mikolajewska-Hanclich I, et al. PIK3CA mutations predict local recurrences in rectal cancer patients. Clin Cancer Res. 2009;15(22):6956-6962.

104. Grimminger PP, Brabender J, Warnecke-Eberz U, et al. XRCC1 gene polymorphism for prediction of response and prognosis in the multimodality therapy of patients with locally advanced rectal cancer. J Surg Res. 2010;164(1):e61-e66.

105. Soumaoro LT, Uetake H, Higuchi T, Takagi Y, Enomoto M, Sugihara K. Cyclooxygenase-2 expression: a significant prognostic indicator for patients with colorectal cancer. Clin Cancer Res. 2004;10(24):8465-8471.

106. Kelley ST, Coppola D, Yeatman T, Marcet J. Tumor response to neoadjuvant chemoradiation therapy for rectal adenocarcinoma is mediated by p53-dependent and caspase 8-dependent apoptotic pathways. Clin Colorectal Cancer. 2005;5(2):114-118.

107. Charara M, Edmonston TB, Burkholder S, et al. Microsatellite status and cell cycle associated markers in rectal cancer patients undergoing a combined regimen of 5-FU and CPT-11 chemotherapy and radiotherapy. Anticancer Res. 2004;24(5B):3161-3167.

108. Brophy S, Sheehan KM, McNamara DA, Deasy J, Bouchier-Hayes DJ, Kay EW. GLUT-1 expression and response to chemoradiotherapy in rectal cancer. Int J Cancer. 2009;125(12):2778-2782.

109. Chen MB, Wu XY, Yu R, et al. P53 status as a predictive biomarker for patients receiving neoadjuvant radiation-based treatment: a metaanalysis in rectal cancer. PLoS One. 2017(9):e45388.
110. Ghadimi BM, Grade M, Difilippantonio MJ, et al. Effectiveness of gene expression profiling for response prediction of rectal adenocarcinomas to preoperative chemoradiotherapy. J Clin Oncol. 2005;23(9): 1826-1838.

111. Akiyoshi T, Kobunai T, Watanabe T. Predicting the response to preoperative radiation or chemoradiation by a microarray analysis of the gene expression profiles in rectal cancer. Surg Today. 2012;42(8): 713-719.

112. Watanabe T, Komuro Y, Kiyomatsu T, et al. Prediction of sensitivity of rectal cancer cells in response to preoperative radiotherapy by DNA microarray analysis of gene expression profiles. Cancer Res. 2006;66(7):3370-3374.

113. Kim IJ, Lim SB, Kang HC, et al. Microarray gene expression profiling for predicting complete response to preoperative chemoradiotherapy in patients with advanced rectal cancer. Dis Colon Rectum. 2007;50(9): 1342-1353.

114. Svoboda M, Sana J, Fabian P, et al. MicroRNA expression profile associated with response to neoadjuvant chemoradiotherapy in locally advanced rectal cancer patients. Radiat Oncol. 2012;7:195.

115. Kheirelseid EA, Miller N, Chang KH, et al. miRNA expressions in rectal cancer as predictors of response to neoadjuvant chemoradiation therapy. Int J Colorectal Dis. 2013;28(2):247-260.

116. Della Vittoria Scarpati G, Falcetta F, Carlomagno C, et al. A specific miRNA signature correlates with complete pathological response to neoadjuvant chemoradiotherapy in locally advanced rectal cancer. Int J Radiat Oncol Biol Phys. 2012;83(4):1113-1119.

117. Zitt M, Zitt M, Müller HM, et al. Disseminated tumor cells in peripheral blood: a novel marker for therapy response in locally advanced rectal cancer patients undergoing preoperative chemoradiation. Dis Colon Rectum. 2006;49(10):1484-1491.

118. Saelen MG, Flatmark K, Folkvord S, et al. Tumor kinase activity in locally advanced rectal cancer: angiogenic signaling and early systemic dissemination. Angiogenesis. 2011;14(4):481-489.

119. Agostini M, Pucciarelli S, Enzo MV, et al. Circulating cell-free DNA: a promising marker of pathologic tumor response in rectal cancer patients receiving preoperative chemoradiotherapy. Ann Surg Oncol. 2011;18(9):2461-2468.

120. Zitt M, Müller HM, Rochel M, et al. Circulating cell-free DNA in plasma of locally advanced rectal cancer patients undergoing preoperative chemoradiation: a potential diagnostic tool for therapy monitoring. Dis Markers. 2008;25(3):159-165.

121. National Institute for Health and Care Excellence: Colorectal Cancer Pathway. London: National Institute for Health and Care Excellence; 2013. Available from: http://pathways.nice.org.uk/ pathways/colorectal-cancer\#path=view\%3A/pathways/colorectalcancer/managing-local-colorectal-tumours. $x m 1 \&$ content=viewnode $\% 3$ Anodes-deciding-whether-to-offer-further-treatment. Accessed April 2, 2013.
OncoTargets and Therapy

\section{Publish your work in this journal}

OncoTargets and Therapy is an international, peer-reviewed, open access journal focusing on the pathological basis of all cancers, potential targets for therapy and treatment protocols employed to improve the management of cancer patients. The journal also focuses on the impact of management programs and new therapeutic agents and protocols on
Dovepress

patient perspectives such as quality of life, adherence and satisfaction The manuscript management system is completely online and includes a very quick and fair peer-review system, which is all easy to use. Visit http://www.dovepress.com/testimonials.php to read real quotes from published authors. 